\title{
Managing Carbon Aspirations: The Influence of Corporate Climate Change Targets on Environmental Performance
}

\author{
Frederik Dahlmann $^{1}$ (1) $\cdot$ Layla Branicki ${ }^{2} \cdot$ Stephen $_{\text {Brammer }}^{2}$
}

Received: 25 August 2016 / Accepted: 3 November 2017 / Published online: 11 November 2017

(C) The Author(s) 2017. This article is an open access publication

\begin{abstract}
Addressing climate change is among the most challenging ethical issues facing contemporary business and society. Unsustainable business activities are causing significant distributional and procedural injustices in areas such as public health and vulnerability to extreme weather events, primarily because of a distinction between primary emitters and those already experiencing the impacts of climate change. Business, as a significant contributor to climate change and beneficiary of externalizing environmental costs, has an obligation to address its environmental impacts. In this paper, we explore the role of firms' climate change targets in shaping their emissions trends in the context of a large multi-country sample of companies. We contrast two intentions for setting emissions reductions targets: symbolic attempts to manage external stakeholder perceptions via "greenwashing" and substantive commitments to reducing environmental impacts. We argue that the attributes of firms' climate change targets (their extent, form, and time horizon) are diagnostic of firms' underlying intentions. Consistent with our hypotheses, while we find no overall effect of setting climate change targets on emissions, we show that targets characterized by a commitment to more ambitious emissions reductions, a longer target time frame, and
\end{abstract}

Frederik Dahlmann

frederik.dahlmann@wbs.ac.uk

Layla Branicki

Layla.branicki@mq.edu.au

Stephen Brammer

stephen.brammer@mq.edu.au

1 Warwick Business School, University of Warwick, Scarman Road, Coventry CV4 7AL, UK

2 Faculty of Business and Economics, Macquarie University, North Ryde, Sydney, NSW 2109, Australia absolute reductions in emissions are associated with significant reductions in firms' emissions. Our evidence suggests the need for vigilance among policy-makers and environmental campaigners regarding the underlying intentions that accompany environmental management practices and shows that these can to some extent be diagnosed analytically.

Keywords Carbon dependency - Climate change targets . Environmental performance · Environmental strategy · Greenhouse gas emissions · Greenwashing

\section{Introduction}

Addressing climate change is among the most pressing ethical challenges facing contemporary business and society (Howard-Grenville et al. 2014; Vatican 2016). Current, unsustainable business models and practices generate profound and varied injustices (Slawinski et al. 2017). The borderless nature of greenhouse gas emissions creates significant distributive, procedural, and spatial challenges in which emissions generated in one part of the world impact geographically distant locations in ways that are further exacerbated by variation in vulnerability and capacity to respond (Haney 2015). Moreover, it is widely recognized that current injustices associated with climate change are likely to intensify over time and extend to future generations (Besio and Pronzini 2014). Businesses are major polluters and already profit at the expense of the broader public through largely costless externalities. They thus face moral responsibilities to mitigate their impacts by reducing their greenhouse gas (GHG) emissions as part of a transition to a sustainable, low-carbon economy (Besio and Pronzini 2014; Haney 2015; Stern 2006). 
Interest in business responses to climate change is reflected in the significant growth of research especially on the strategies and practices that aim to reduce firms' carbon footprints ${ }^{1}$ (Aragón-Correa et al. 2016; Delmas and Toffel 2008; Hahn et al. 2015; Wright and Nyberg 2016). Despite increasing scrutiny and pressure to address environmental issues associated with their activities, empirical evidence suggests that firms' commitment to improving environmental impacts varies significantly due to the cognitive, strategic, technical, and managerial challenges in operating in more sustainable ways (Alt et al. 2015; Hussain et al. 2016; Post et al. 2015). Prior research has identified a number of reasons for businesses to engage in environmental management, including pre-empting or responding to regulatory pressures (Berrone and Gomez-Mejia 2009; Boiral 2007; Delmas and Toffel 2008; Delmas and Montes-Sancho 2010), reducing costs by eliminating waste (Porter and Van der Linde 1995), attracting environmentally conscious customers, employees, and investors (Alt et al. 2015; Flammer 2013), and building and sustaining legitimacy among external stakeholders, often by imitating peer organizations (Bansal 2005; Bansal and Clelland 2004; Berrone et al. 2017). Research suggests that the levels and forms of environmental pressures and opportunities are strongly associated with firm characteristics, including industry sector and size (Darnall et al. 2010), and that these translate into variations of organizational commitment to environmental issues (Sharma 2000). This variation in the intensity and types of motives to address environmental impacts is mirrored in the voluntary adoption and implementation of environmental tools, practices, and initiatives such as (certified) environmental management systems (Boiral 2007), public commitments to act on environmental issues (Delmas and Montes-Sancho 2010), and disclosure of environmental achievements and impacts (Andrew and Cortese 2011; Hahn et al. 2015).

Yet one major concern is that pressures on firms to act on environmental issues have also generated incentives for firms to communicate environmental commitments that are not reflected in concrete action on environmental issues (Aragón-Correa et al. 2016). Typically, critical research argues that firms engage in "greenwash," defined as "any communication that misleads people into adopting overly positive beliefs about an organization's environmental performance, practices or products" (Lyon and Montgomery 2015 , p. 226), although recent research has suggested that greenwashing is only one of many forms of decoupling whereby environmental communication and performance

\footnotetext{
1 'Corporate carbon footprints' are a widely used metaphor for firms' greenhouse gas (GHG) emissions contributing to anthropogenic climate change. Carbon footprints include carbon but also other types of GHG emissions. In this paper, we use carbon footprints and GHG emissions interchangeably.
}

differ at the firm level (Bowen 2014; Crilly et al. 2012; Lyon and Maxwell 2011). Whatever the underlying processes and mechanisms, much research echoes a perception that some firms adopt a relatively symbolic, or decoupled, approach to managing their environmental impacts, while others are committed to more substantive implementation of their environmental commitments (Berrone et al. 2017). Calls continue for a critical approach toward examining the outcomes of especially voluntary environmental practices (Bowen 2014, 2017; Delmas and Burbano 2011).

Here, we focus on a specific environmental management practice that has proliferated in recent years but remains relatively little studied: firms' climate change targets. A growing number of global initiatives are supporting corporate non-financial target-setting efforts, including Science-Based Targets (GHG emissions), Pivot Goals (sustainability), the Forest500 (deforestation), the EP100 (energy productivity), and the RE $100^{2}$ (renewable energy), with large firms now commonly setting climate change targets. For example, Walmart states it has " a long-term, aspirational goal to be supplied $100 \%$ by renewable energy." Similarly, Austrian electric utility "VERBUND aims to be carbon neutral by 2050" and the German car manufacturer BMW Group "will reduce total $\mathrm{CO} 2$ emissions of its production network from 1990 to 2020 by 30\%." Dow Chemical declares, "the current long term target is that scope 1 and scope 2 Kyoto GHG emissions will not exceed 1990 levels through 2025. The strategy is to grow the company while not increasing GHG emissions," and UK retailer Tesco has the "target to be a zero-carbon business, without purchasing offsets, by 2050.” While research has recently begun to explore the role and effectiveness of companies setting a range of sustainability targets, particularly as part of executive remuneration schemes (Ioannou et al. 2016; Kolk and Perego 2014; Maas 2016; Maas and Rosendaal 2016; Pinkse and Busch 2013; Pinkse and Kolk 2009), there remains a notable lack of empirical evidence regarding the effectiveness of targets on non-financial performance outcomes, and the contingencies that intervene in these processes (Di Norcia 1996; Ioannou et al. 2016; Russo and Harrison 2005).

In this paper, we investigate the relationships between the presence and nature of firms' climate change targets and changes in their corporate carbon footprints. Drawing on environmental management literature, we develop a conceptualization that views climate change targets as reflecting firms' range of strategic and symbolic intentions about environmental performance improvement. We hypothesize that the impacts of such targets on GHG

\footnotetext{
${ }^{2}$ For more details, please see www.sciencebasedtargets.org; www. pivotgoals.com; www.forest500.org; www.theclimategroup.org/project/ep100; www.there100.org.
} 
emissions trends depend on the extent to which they are underpinned by substantive intentions to address climate change. We test our hypotheses in the context of a sample of over 1000 global companies that are participants in the CDP, for which unique data concerning the detailed character of their GHG emissions reduction targets are available.

Our paper makes two important contributions. First, we contribute significantly new empirical evidence regarding the influence of voluntary managerial practices on firms' environmental performance. Our aim is to "peel back the onion" of environmental performance (Russo and Harrison 2005 , p. 582 ) by providing new evidence into the importance of the presence and nature of firms' climate change targets for emissions reduction, thus overcoming some of the methodological challenges that have hampered prior research on corporate environmental performance. Our focus on the influences on firms' greenhouse gas emissions generates new evidence and insights into whether and when specific voluntary managerial practices can help firms addressing important global sustainability challenges, such as increasing their efforts toward mitigating climate change.

Second, we contribute new evidence to the broader debates concerning the role of organizational aspirations in shaping organizational, particularly non-financial, outcomes. Specifically, our paper develops a conceptualization of climate change targets that differentiates their application as either substantive strategic management or symbolic legitimization tools. By differentiating between the intentions of employing climate change targets, we shed new light on the efficacy and limitations of non-financial target setting and the circumstances in which they are most likely to improve performance. Thus, we extend the very limited body of research on targets, which has long been constrained because prior research has seldom been able to directly observe outcomes of target-setting processes, instead drawing from patterns in prior organizational performance to make inferences regarding levels of, and likely changes to, firms' organizational aspirations (Bromiley and Harris 2014; Washburn and Bromiley 2012). We extend theory on target setting and begin to grow empirical research on the efficacy of climate change targets by critiquing their use in circumstances where firms seek to gain purely symbolic benefits, and provide evidence of the impacts of targets on environmental performance (Hahn et al. 2014).

The next section develops our conceptual model and outlines our hypotheses. We then describe our methods and findings before discussing the implications of our analysis. A final section concludes.

\section{Conceptual Development and Hypotheses}

\section{Prior Research on Non-Financial Performance Targets}

Pinkse and Busch (2013) summarized four broad factors enabling and constraining the use of carbon norms. These carbon norms reflect public declarations and voluntary commitments to constrain their firms' impact on the global climate and are thus largely equivalent to climate change targets. Both company image and aim are argued to shape how firms seek to improve their strategic positioning by using climate change targets (Pinkse and Busch 2013). The authors distinguish between aims of strategic differentiation from competitors and standardization to level industry practices. By contrast, companies can also set targets to signal either a desired future image or an improved current image. In the latter cases, the underlying intention is one of symbolic impression management and legitimacy enhancement, often associated with accusations of greenwash (Berrone et al. 2017; Delmas and Burbano 2011; Pinkse and Busch 2013). This variation in approaches is explored in four Dutch case studies by Kolk and Perego (2014) who struggled to find unanimous evidence on whether corporate social performance (CSP) targets in executive remuneration reflect either substantive efforts to address social responsibility or more symbolic efforts of window dressing, potentially even the gaming of bonus payment schemes. Exploring the use of climate change targets in carbon reduction projects, Ioannou et al. (2016) found that firms setting more difficult targets complete a higher percentage of their carbon emissions reduction targets and that this relationship is negatively moderated by the provision of monetary incentives. Arguably, target difficulty could be equated to substantive intentions reflecting more sincere attempts to improve environmental performance.

Maas and Rosendaal (2016) also explored the use and nature of broader sustainability targets in executive remuneration among a sample of global multinationals finding significant variation in target-setting behaviors. Yet although targets could generally vary by temporal focus (short term and long term) and by sustainability content (environmental, social or a combination of both), they were chiefly used by firms in dirtier industries and predominantly focused on short-term outcomes and social issues. Studying the effectiveness of corporate social performance targets among the S\&P 500, Maas (2016) found that that while qualitative, soft CSP targets in executive compensation appear to be mainly used for symbolic reasons, only quantitative, hard targets were showing improved CSP results, thus being suggestive of substantive intentions. Further evidence on targets and compensation regimes suggests that when tied to financial incentives, such targets may lead to environmental 
performance improvements (Berrone and Gomez-Mejia 2009; Cordeiro and Sarkis 2008; Russo and Harrison 2005).

In sum, extant findings paint a patchy, and particularly often executive-level focused, picture of the use and effectiveness of non-financial performance targets. Importantly, however, the repeated calls for and references to drawing a distinction between substantive and symbolic intentions underpinning target-setting behavior in this context highlight the need for both conceptual and methodological clarity during hypothesis specification.

\section{Conceptual Model}

Our theorization of the relationship between firms' climate change targets and their environmental outcomes is grounded in prior research that recognizes that a wide range of intentions underpin firms' environmental management activities (Berrone and Gomez-Mejia 2009; Kolk and Perego 2014) and that the relationship between these activities and environmental outcomes is therefore complex (di Norcia 1996). Ambiguous evidence in relation to environmental management practices in general (Hussain et al. 2016), and particularly target setting (Berrone and Gomez-Mejia 2009; Cordeiro and Sarkis 2008; Russo and Harrison 2005), has fueled debate regarding the limitations of prior research and the merits of various approaches to managing environmental impacts (Maas and Rosendaal 2016; Hahn et al. 2016; Wright and Nyberg 2016).

Substantively, research has highlighted in increasingly nuanced ways processes and mechanisms by which stated, observed, or communicated environmental intentions in companies might be systematically unrelated to, or "decoupled" from, their emissions and impacts (Delmas and Montes-Sancho 2010). Classically, the absence of clear reductions in emissions and impacts associated with a range of environmental management practices, communications, and stated intentions has been understood to reflect willful, strategic attempts to mislead stakeholders through "greenwashing" activities (Aragón-Correa et al. 2016). Where the introduction of environmental initiatives reflects predominantly legitimacy-enhancing intentions, scholars speak of symbolic adoption and implementation (Bansal and Clelland 2004; Berrone and Gomez-Mejia 2009; Boiral 2007; Delmas and Toffel 2008; Delmas and Montes-Sancho 2010), whereby firms' intent to achieve specific environmental ends is partial at best. In the context of setting climate change targets, prior research has suggested that target setting reflects attempts to present a certain image designed to create favorable stakeholder impressions of the company's operations and ambitions (Pinkse and Busch 2013). These legitimacy-driven intentions may be caused by significant stakeholder pressures, including those from NGOs, media, and investors (Bansal and Clelland 2004; Darnall et al.
2010; Flammer 2013). Alternatively, growing adoption of various environmental practices may simply reflect companies mimicking each other's behavior or attempts to preempt regulatory intervention, once again with ambiguous implications for firms' environmental impacts (Bansal 2005; Pinkse and Busch 2013). More recently, more sympathetic accounts have emphasized alternative processes by which such decoupling arises and persists (Pache and Santos 2013; Wright and Nyberg 2016).

What these discussions share is the recognition that understanding the underlying intentions and commitment to addressing environmental impacts is essential to examining the relationship between a given environmental management initiative and its effects on environmental outcomes. Broadly, these intentions reflect an underlying spectrum of the degree to which they embody a commitment to improving environmental outcomes, with relatively symbolic (low environmental commitment) intentions at one end of the spectrum and relatively substantive (high environmental commitment) intentions at the other. For simplicity, our conceptual model (summarized in Fig. 1) dichotomizes the spectrum of underlying intentions for environmental practices into two alternative "modes" of intentions that underpin firms' decisions to set climate change targets. In the first, targets are primarily conceived of as tools of impression management among external stakeholders-they are classically symbolic in nature and are not associated with any real intention to improve environmental performance. In the second mode, targets are substantive in nature and reflect a firm's aim to understand, manage, and reduce its environmental impacts over time. Since "true" intentions are unobservable, we propose that the nature of climate change targets as expressed through key target characteristics acts as a proxy for underlying intentions. We then hypothesize that there is a relationship between this degree of substantiveness of climate change targets and improvements in environmental performance. Moreover, to account for varying firm and industry-level contingencies affecting target-setting behavior and potential for environmental improvement, we differentiate our analysis by firms' carbon dependency.

\section{The Influence of Climate Change Targets on Environmental Performance}

Having outlined our overall model, we begin by exploring firms' intentions and considerations when setting emissions targets. Building upon the dichotomy between substantive and symbolic intentions for setting climate change targets, we argue that only when substantive intentions to improve environmental performance underpin target-setting behavior will they be effective. Substantive intentions may be altruistic or instrumental, or both (Hahn et al. 2016), but they must be minded toward measurable performance improvements 
Fig. 1 Research model summarizing impact of climate change target characteristics on firms' environmental performance

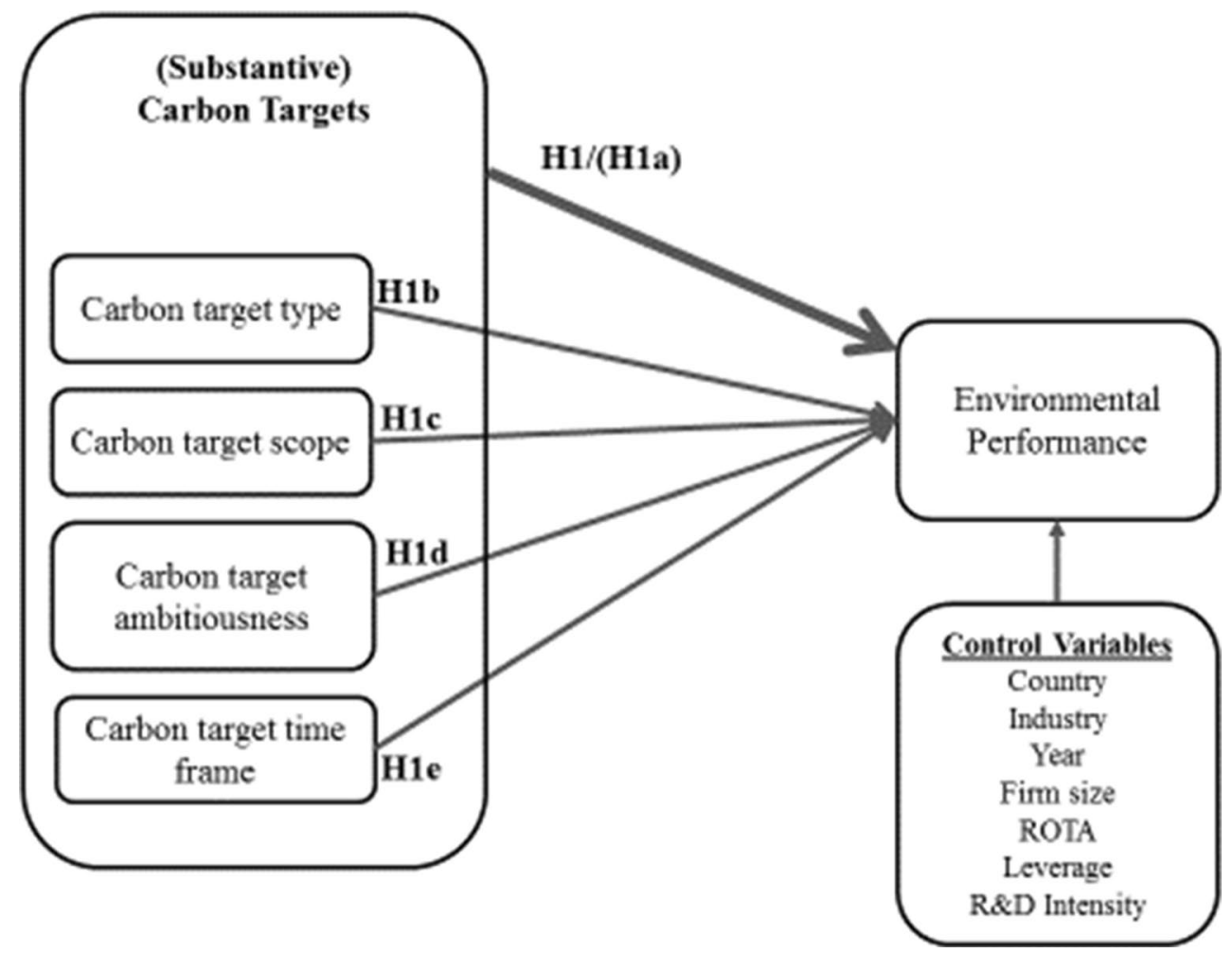

(di Norcia 1996). In these circumstances, carbon performance targets provide firms with an opportunity to develop unique organizational capabilities, which both address environmental impact and may be of value to the firm's broader financial performance and strategic aspirations (Bansal 2003; Sharma 2000).

Consequently, substantive climate change targets have the potential to affect both environmental performance directly and wider organizational performance more obliquely (Foss and Lindenberg 2013). By aspiring to improve their environmental performance in a significant manner, firms commit themselves to outcomes hitherto unthinkable and unobserved. Targets trigger cognitive and motivational processes (Sitkin et al. 2011; Zhang and Jia 2013) which direct, energize, and encourage persistence needed to work toward their achievement, and which indirectly stimulate changed behaviors inside the organization (Locke and Latham 2009). Consequently, targets have the potential to unleash creativity, urgency, and excitement among employees with the purpose of collaborating, learning, innovating, and deviating from existing routines, habits, and practices to drive significant performance improvements (Halme 2002; Winter 2000). Substantive goals therefore provide the vital link between individual actions and organizational achievement by affecting the necessary cognition and joint production motivation of all organizational members, not just of top management (Foss and Lindenberg 2013). By contrast, firms chiefly motivated by a desire to enhance their reputation among stakeholders are likely to set targets for reasons unrelated to actual or significant performance improvements. We therefore develop the following baseline hypotheses:

Hypothesis 1 (H1) There is no overall relationship between the presence of climate change targets and improvements in environmental performance (i.e., reductions in emissions).

Hypothesis 1 (H1a) Firms with substantive climate change targets are associated with improvements in environmental performance (i.e., reductions in emissions).

\section{Characteristics of Substantive Climate Change Targets}

Climate change targets are highly heterogeneous in multiple dimensions, and thus, once a firm has decided to articulate explicit environmental objectives, there is a need to agree on and specify more technical/operational details (Maas and Rosendaal 2016; Pinkse and Kolk 2009). For example, choices include target purpose (internal substantive improvement tool vs. external symbolic signal); whether to target absolute emissions reductions or relative improvements (e.g., per unit of output, energy intensity); target coverage (energy use and/or GHG emissions); organizational scope (direct and/or indirect emission); and geographic scope (local and/ or global or a combined, differentiated approach) (Pinkse and Kolk 2009). We argue that the detailed characteristics 
of firms' targets are critical in diagnosing the underlying intentions that accompany them and therefore their likely impacts on environmental outcomes.

In relation to evaluating the relative degree of substantiveness when examining a firm's climate change targets, we build on prior literature by identifying the following four target criteria: target type (absolute vs. relative emissions reductions targeted); target scope (broad vs. narrow scope of emissions reductions targeted); target ambitiousness (scale of emissions reductions targeted); and target time frame (period over which emissions reductions are targeted) to develop our main hypotheses (Fig. 1). Effectively, we argue that substantive intentions to reduce firms' GHG emissions can be diagnosed by climate change targets that are absolute, include a broader range of emissions scopes, are more ambitious, and include longer target time frames. By contrast, we would characterize climate change targets that are intensitybased, include a narrower range of emissions scopes, are less ambitious, and include shorter target time frames, as comparatively symbolic in their intention to address climate change and thus likely to be more consistent with greenwash.

Target type Companies mainly distinguish between two different types of climate change targets: First, absolute targets which envisage a reduction in firms' total levels of GHG emissions over time. By contrast, intensity targets reflect ambitions to improve energy efficiency and/or greenhouse gas emissions at a more relative level (for example, to reduce $\mathrm{CO}_{2}$ emissions per $\$$ of sales, or per employee) which therefore do not necessarily translate into absolute (or total) greenhouse gas emissions reductions at the firm level (Slawinski et al. 2017; Pinkse and Kolk 2009), a key criterion in the efforts behind international climate change mitigation policies and associated reduction pathways (Stern 2006; UNFCCC 2015). There is thus a need to critically assess the contribution of intensity targets as a means of driving significant environmental performance improvements. Specifically, we see intensity targets as relatively weaker, outward-looking, and potentially more symbolic expressions of firms mainly seeking to enhance corporate image. Given that they are designed to allow for unconstrained growth in corporate activity, they are more easily achievable compared to absolute targets which foresee complete decoupling of economic growth and emissions. Intensity targets also exemplify widespread belief that relative efficiency improvements are closely associated with cost savings (Porter and Van der Linde 1995), thus providing extrinsic incentives regardless of organizational attitudes toward climate change. This puts into question the effectiveness of intensity targets beyond what is generally seen as best practice from a micro-economic perspective. By contrast, absolute targets set an inward-looking hard goal more closely aligned with societal interests of climate change mitigation and whose achievement is prima facie antithetical to a company's overall performance (Pinkse and Kolk 2009). We therefore hypothesize:

Hypothesis 1b (H1b) Firms with absolute climate change targets are associated with improvements in environmental performance (i.e., reductions in emissions).

Target Scope Firms' next choice about specifying their climate change targets relates to the different types of scopes of emissions. A primary distinction is drawn between direct ("scope 1" emissions) and indirect emissions ("scope 2" emissions). Direct emissions stem from activities immediately controlled or owned by the reporting firm (for example, from on-site production processes, direct use of fossil fuels in boilers and furnaces, and in-house power generation); indirect emissions arise from firms' use of purchased electricity as provided by the grid. A third but significant category of emissions ("scope 3" emissions) includes emissions derived chiefly from a firm's supply chain (i.e., carbon embodied in procured goods and services), from business travel, and those associated with external distribution (WBSCD/WRI 2011). Since scope 3 emissions are harder to evaluate and measure accurately, these data remain comparatively patchier and less reliable but have become an emerging topic of research (e.g., CDP 2017; Chen 2017).

For the purposes of this research, we mainly distinguish between broad and narrow scopes of emissions reductions targeted whereby only a broader, all-encompassing view of a firm's scope of emissions is considered reflective of substantive intentions to improve environmental performance. In other words, we argue that only climate change targets including at least two types of scope signal substantive intentions to fully address climate change concerns. By contrast, narrower scopes of emissions targeted evoke the image of "cherry-picking" whereby firms symbolically target specific scopes of emissions that are either most likely to yield reductions anyway (for example, due to fuel switching), or are least likely to matter in the grand scheme of their corporate carbon footprints (Pinkse and Kolk 2009). We therefore hypothesize:

Hypothesis 1c (H1c) Firms with a broader scope of climate change targets are associated with improvements in environmental performance (i.e., reductions in emissions).

Target ambitiousness The third target characteristic reflects general ambitiousness regarding the scale of emissions reductions targeted. More specifically, it relates to the core premise behind target setting in that ambitious targets, that is, those including a larger percentage of emissions to be reduced, are more likely to be effective given our initial discussion on the target-setting literature (Ioannou et al. 2016). Quantitatively more ambitious targets (Maas 2016) therefore 
reflect substantive intentions which create the internal conditions needed to spur large-scale innovation and performance improvement (Collins and Porras 1994; Halme 2002; Winter 2000) but which must also take into account "historical achievements, growth paths, and future plans of the company in industry and (inter)national contexts" (Pinkse and Kolk 2009, p. 65).

One issue is that this level of ambition is likely to be context dependent. Given the debate over the relative merits of intensity vs. absolute targets ( $\mathrm{H} 1 \mathrm{~b}$ ), one argument could be that simply having an absolute target is by itself reflective of significant ambition. Deciding exactly what level of ambition to target is subject to much debate and is, for instance, considered in more detail by the "Science-Based Targets" initiative, which provides a methodology for setting climate change targets consistent with climate science. Several contextual factors play a role in this process of deciding on the level of target ambition, including industry and the time frame (H1e) over which they apply. For the purposes of our research, we argue that while overly ambitious targets may demotivate individuals' responses to these targets, quantitatively greater climate change targets are reflective of greater ambition, which is needed to provide a radical stimulus for innovation and organizational change that could subsequently lead to environmental performance improvements.

Hypothesis 1d (H1d) Firms with more ambitious climate change targets are associated with improvements in environmental performance (i.e., reductions in emissions).

Target time frame Finally, while target ambitiousness certainly represents one key metric of substantive intentions, the period over which such targets apply adds further nuance. Firms that set relatively short-term targets (Maas and Rosendaal 2016) may do so because of some form of prior knowledge about the likelihood of achieving said targets, for example, because there is some form of certainty about reaching them ("low-hanging fruits") and/or a coincidence with remuneration cycles (e.g., bonus payments) (Kolk and Perego 2014). In these instances, the reductions do not fulfill the criteria associated with substantive targets. By contrast, firms committing to long-term emissions reductions are presumably more realistic about the need for implementing significant long-term goals as advocated by climate science and international policy (Slawinski et al. 2017). Rather than chasing quick wins, firms with long-term targets are more likely to aim for fundamentally challenging and major strategic change. In that sense, the longer the period of emissions reductions targeted (typically the further into the future the target year), the more these organizations appreciate the need for investment in a broad range of activities and collaboration to identify cross-sector solutions (Slawinski and Bansal 2012, 2015). One plausible counter-argument, however, could be that long-term goals may reflect managerial decisions to shift the firm's climate change responsibility to future generations of executives and employees, for example, by relying on a technology yet to be commercialized, or by deferring instant implementation to avoid stakeholder scrutiny (Delmas and Burbano 2011; Pinkse and Busch 2013). Given such ambiguity, we state our hypothesis in line with our main argument, while acknowledging the potential for opposite effects to materialize:

Hypothesis 1e (H1e) Firms with longer climate change target periods are associated with improvements in environmental performance (i.e., reductions in emissions).

\section{The Moderating Influence of Firms' Carbon Dependency}

Having developed our hypotheses on how the characteristics of firms' climate change targets influence the likelihood that they lead to reductions in firms' emissions, next we discuss contingencies that are likely to shape their effectiveness. Prior research has noted that the achievement of targets can be impeded when actors find it difficult to identify with them, or when targets provoke disappointment and demotivation because progress is slow. Particularly since climate change targets may by their nature be associated with significant uncertainty in relation to the processes and strategies for implementation, they can create internal resistance (Mishina et al. 2010; Sitkin et al. 2011; Zhang and Jia 2013). For example, there is the recognition that technological and operational "lock-in" due to long and large-scale investment cycles determines firms' performance levels for years if not decades (Unruh 2002). Firms' industry sector, size, and existing environmental footprints can constrain the scope for performance improvements, thus reducing the salience and level of strategic prioritization given to environmental issues (Bundy et al. 2013). Pinkse and Busch (2013) referred to this as carbon dependency, defined as a firm's "potential to reduce its GHG emissions over time in a cost-effective way" (p. 640). This carbon lock-in or carbon dependency indicates firms' level of economic feasibility for significantly and credibly reducing their carbon footprints over time. Often there are also powerful economic forces at play whereby carbon dependency either remains a costless externality or only has a marginal impact on overall financial performance. In these instances, environmental improvement is economically disincentivized, thus impacting on managerial decision making in response to the presence of climate change targets (Eccles et al. 2012).

For example, the interpretation of environmental issues as potential threats to the established business model or industry order (Sharma 2000) forms a significant challenge for firms with high carbon dependency 
(Ioannou et al. 2016; Pinkse and Busch 2013). Coupled with inconsistent stakeholder engagement, for example, when firms with high carbon dependency seek to make improvements while at the same time lobbying against regulatory measures, this can result in managerial tension and confusion regarding the real intentions and incentives behind corporate behavior (Hahn et al. 2014). In other words, despite the formal existence of climate change targets, managers and employees in highly carbon-dependent firms may not actually be making efforts to reach them. For example, Cordano and Frieze (2000) found a positive relationship between a facility's amount of past source reduction activity and environmental managers' preference to implement source reduction activities in the future. Similarly, Branzei et al. (2004) studied the intra-organizational feedback loops involved in environmental strategy formation and found that organizational goals adjust in response to performance signals—success stimulates more difficult goals, whereas failure triggers downward adjustments in goals or withdrawal of effort. Thus, where managers interpret past performance as failure and a losing course of action, climate change targets are less likely to lead to improved performance but are viewed with suspicion and apprehension and resisted by individuals who interpret them as a threat to their identity and organizational strategy.

From a symbolic perspective, then, research suggests that firms within polluting industries (i.e., those likely to be associated with high carbon dependency) are more likely to adopt environmentally friendly processes including targeted CEO rewards to achieve legitimacy (Berrone and Gomez-Mejia 2009; Maas and Rosendaal 2016; Russo and Harrison 2005). Consequently, high carbon dependency can undermine the confidence in the achievement of the targets and so reduce commitment to those aspirations. By contrast, in sectors with low carbon dependency, substantive climate change targets may lead to significant innovation to address a relatively less salient, but easier to address and, nonetheless, highly competitive issue. Combined with the fact that industries with lower carbon dependency also tend to be end-consumer facing, there is potentially a stronger argument for these companies to express substantive intentions for addressing climate change concerns. Hence, we hypothesize that carbon dependency affects our hypotheses on the effectiveness of substantive climate change targets:

Hypothesis 2 (H2) For firms with low carbon dependency, the use of substantive climate change targets will be associated with positive effects on environmental performance (i.e., reductions in emissions).

\section{Methods}

\section{Sample}

Our research draws on data provided by the CDP (formerly Carbon Disclosure Project), an initiative led by a consortium of over 767 institutional investors with cumulatively over US\$92 trillion of assets under investment that seeks improvements into the transparency and management of environmental issues, principally responses to climate change, among leading global companies. Each year since 2002, the CDP asks the largest companies in the world to complete a series of questionnaires that probe various aspects of their climate change strategies. Company responses to the CDP questionnaire are typically made publicly available on the CDP Web site, thus providing a unique level of transparency and disclosure in relation to environmental management and performance. Participation in the CDP's annual survey is voluntary, and the levels of participation (by both firms and institutional investors), information disclosure, and the depth of information requested by the CDP have all grown substantially over time. In 2014, the latest year for which data are available to us, over 4500 companies from around 50 different countries participated in the CDP and disclosed detailed information about their management of climate changerelated issues. Despite this growth in data availability, the use and validity of CDP data in academic research remains contested (Andrew and Cortese 2011). To address these concerns, our sampling and research approach is based on the following observations and decisions.

We sample from the CDP by restricting our attention to those companies that actively provide information about their climate change targets. We do so first because not all survey respondents disclose this type of information; many firms that do, however, are willing to admit they do not have targets in place. By choosing this sampling frame, we seek to ensure that only active disclosure of target information is included in our sample rather than inferred. Second, the more recent survey data provide responses that include target information in a format which has since then remained consistent following the standardization of response categories. This provides some assurance that a more consistent definition of emissions targets has been applied. This results in a sample of 3982 firm-year observations, based on 1335 unique firms from 42 countries and across 108 industry sectors that disclosed climate change target information to the CDP between 2010 and 2013. We complement this sample with CDP data on GHG emissions as well as with financial data from Thomson Reuters Datastream between 2009 and 2014 to include both leading and lagging data. 


\section{Research Approach}

The aim of our research is to investigate the relationship between different forms of climate change target-setting behaviors on subsequent changes in firms' GHG emissions. However, in line with similar research in this area, our study is complicated by the fact that firms' propensity to set climate change targets and their emissions performance may be closely linked. Therefore, to overcome potential selection and endogeneity effects, we employ a Heckman two-stage research approach (Delmas and Montes-Sancho 2010; Heckman 1979). Specifically, in the first stage, we estimate the likelihood of firms setting any kind of climate change target in the first place. We use a binary logit model based on several control variables and industry-adjusted carbon intensity as the key independent variable in our estimation of this probability. In stage two of our main analysis and model, we then use the estimated probabilities of whether firms are likely to set a climate change target as a key control variable in our unbalanced and pooled linear regression models before adding various target characteristics as independent variables to test our hypotheses. This widely used approach should overcome the likely challenge that prior emissions, targets, and subsequent emissions changes are statistically linked. To summarize:

(1) Probability Any Target ${ }_{(t)}=\mathrm{f}$ (Industry, Country, Year, Leverage $_{(t-1)}$, Size $_{(t-1)}$, R\&D Intensity $(t-1)$, ROTA $_{(t-1)}$, Ind.-adjusted Carbon Intensity $(t-1)$

(2) Environmental Performance $=\mathrm{f}$ (Industry, Country, Year, Leverage $_{(t)}, \operatorname{Size}_{(t)}, \mathrm{R} \& D_{\text {Intensity }}(t)$, ROTA $_{(t)}$, Probability Any Target $(t)$, Climate Change Target characteristics $\left._{(t)}\right)$

We generally employ a lagged model structure to explore the relationship between (and ultimately the effects of) climate change targets and environmental performance. Specifically, our model tests whether the presence and characteristics of climate change targets indicated by firms to be in place predict subsequent emissions changes. In all models in stage two, the absence of climate change targets (of any kind) acts as the comparator.

\section{Dependent Variable}

Our dependent variable environmental performance is operationalized using firms' greenhouse gas emissions, also known as carbon footprints. Measurement of firms' carbon footprints is a complex and information-intensive process characterized by the presence of multiple approaches and competing evaluation methodologies. Therefore, we begin by summing firms' scope 1 and scope 2 emissions to capture a firm's total carbon footprint in each year before calculating 1-year percentage changes in firms' total GHG emissions. This measure of firms' environmental performance is therefore based on absolute changes in emissions, reflecting substantive (as opposed to relative, i.e., intensity) improvements. Our operationalization is consistent with scientific assessments of the need for global GHG emissions to peak and decline, rather than simply to grow less strongly, to avoid 'serious climate change' (UNEP 2015; UNFCCC 2015). It also follows recent scholarly calls for more research on absolute emissions changes as a measure of environmental performance (Slawinski et al. 2017). We also focus on the percentage changes in firms' GHG emissions, rather than a comparison of annual levels of emissions, to help strengthen the causal logic of our analyses as firms' levels of emissions tend to be correlated due to the comparatively small changes over short periods of time. In fact, initial data inspection revealed that firms' environmental performance tends to cluster around $0 \%$ indicating the widespread absence of significant short-term movements in carbon footprints.

\section{Independent Variables}

\section{Industry-Adjusted Carbon Intensity (stage one only)}

To account for the possible influence that firms' prior carbon footprints have on their likelihood of setting any kind of climate change target in the first place, again we calculate for each firm-year the sum of scope 1 and scope 2 emissions measured in tons of $\mathrm{CO}_{2}$ equivalents of all greenhouse gas (GHG) emissions. We then create a more relative measure of carbon intensity that accounts for firms' economic performance. To that end, we first divide firms' annual level of total emissions by their respective levels of total sales before calculating the natural logarithm (Luo 2017). Finally, to account for industry relevance of carbon intensity, we subtract firms' respective sector mean of carbon intensity (Luo 2017). The formulae below summarize our measurement approach:

(3) In CARBON INTENSITY $(t-1)=$ ln (Scope $1_{(t-1)}+$ Scope $\left.2_{(t-1)}\right) /$ Total Sales $(t-1)$

(4) In INDUSTRY ADJUSTED CARBON $\operatorname{INTENSITY}_{(t-1)}=\ln \operatorname{CARBON}_{\operatorname{INTENSITY}_{(t-1)}}-$ (INDUSTRY MEAN $\ln$ CARBON INTENSITY $\left._{(t-1)}\right)$

where the industry mean is calculated for each of the 108 industries covered by our data.

Climate change targets We draw on Sect. 3 of the CDP questionnaire to construct variables that measure the substantiveness of corporate carbon aspirations. As elaborated before, corporate climate change aspirations take a variety of forms (Pinkse and Kolk 2009). Defining and operationalizing substantive carbon goals therefore require careful 
consideration and specification. Target information either comes in the form of CDP standardized multi-choice responses which we further summarize as detailed below or allows respondents to provide numerical values. Companies often give details on more than one target in place in the same year. They may set several absolute and intensity targets, which relate to different scopes of emissions covered, base and target years, percentages, and other metrics. Given such heterogeneity, we summarized this information at the firm-year level by (a) capturing whether firms generally had targets in place and (b) calculating the means of linear variables to summarize target details. We distinguish between the following variables:

Target type We use three different measures to study the impact of different climate change target types. First, we create an ordinal variable that captures the increasing likelihood of addressing climate change in a substantive manner. It assigns $1=$ no target in place; $2=$ intensity target(s) only; $3=$ absolute target(s) only; $4=$ both intensity and absolute targets in place. This target type variable is designed to test whether there is some form of relationship between different arrangements of climate change targets and environmental performance. Second, we create two simple binary dummy variables each for the presence of intensity targets and for absolute targets. Finally, we also include the actual "number of" intensity and absolute targets each. Our aim is to understand to what extent climate change target types are important characteristics in shaping firms' environmental performance.

Target scope We create simple binary dummy variables each for the presence of targets that relate to scope other; scope 1; scopes 1 and 2; scopes 1, 2, and 3; scope 2 only; scope 3 only. The purpose is to differentiate between the different emissions scopes that firms can target for improvement.

Target ambitiousness We calculate firm-year means of percentage reductions in emissions targeted from base year;

Target time frame We calculate firm-year means of target periods measured in years. Target periods are calculated by subtracting the target years from the respective base years.

\section{Carbon Dependency}

Finally, to test whether target effectiveness is shaped by firms' carbon dependency, for our second hypothesis $\mathrm{H} 2$ we rerun our previous analyses based on two subsamples. We split our sample into high and low carbon dependency by separating observations at the 50th percentile value (-0.0159) for firms' industry-adjusted carbon intensity as calculated before. We employ the subsampling approach since this variable is used in the estimation of the likelihood that firms are setting climate change targets in stage one; hence, reusing the same variable as moderator in stage two is likely to create multi-collinearity problems.

\section{Control Variables}

In addition to our variables of interest, we control for several firm characteristics that have been shown to influence firms' environmental responsiveness (Berrone and Gomez-Mejia 2009; Cordeiro and Sarkis 2008; Pinkse and Busch 2013). They include country (captured here through the inclusion of a series of country fixed effects), industry sector (captured through the inclusion of a series of 2-digit SIC fixed effects), year (captured through the inclusion of a series of binary variables for each year), firm size (captured by the natural logarithm of the number of employees), ROTA (captured by the ratio of pre-tax profits to total assets), leverage (captured by the ratio of total debt to total assets), and $R \& D$ intensity (captured by the ratio of $R \& D$ expenses to total assets). To assess whether our sample suffers from problems related to multi-collinearity, we calculate the variance inflation factor (VIF) for each variable finding that VIFs were in the range of 1-5 well below the threshold of 10 suggested as indicative of multi-collinearity problems (Belsley et al. 1980). Furthermore, none of the pairs of independent variables are correlated beyond the threshold value of 0.8 . We are therefore satisfied that multi-collinearity is not a problem on this occasion (O'Brien 2007). Descriptive statistics and bivariate correlations between our measures are reported in Table 1 . They show that out of a total of 3982 firm-year observations, $3786(95 \%)$ have some form of target in place. Out of those, $3186(80 \%)$ are intensity targets, while 3087 are absolute targets (78\%). Most observations target scopes 1 and $2(1923 ; 48 \%)$, followed by scope 1 only $(711 ; 18 \%)$ and a combination of scopes 1,2 , and $3(675 ; 17 \%)$.

\section{Results}

We begin our findings with the results from our stage one analysis (Table 2). Here we use a binary logit model to predict the likelihood that firms set any kind of climate change target. Using industry-adjusted carbon intensities as key explanatory variable, the results of the first stage model show that this measure of prior emissions is not a significant predictor of firms having any kind of climate change target as most of this probability is explained by firm size. In other words, more than firms' prior carbon intensities, it is their size (here measured by employees) which explains whether firms are likely to set a climate change target. Of course, size and emissions are also strongly correlated, but we find that larger firms are more likely to set a climate change target. Our model correctly predicts $94 \%$ of observations and we 


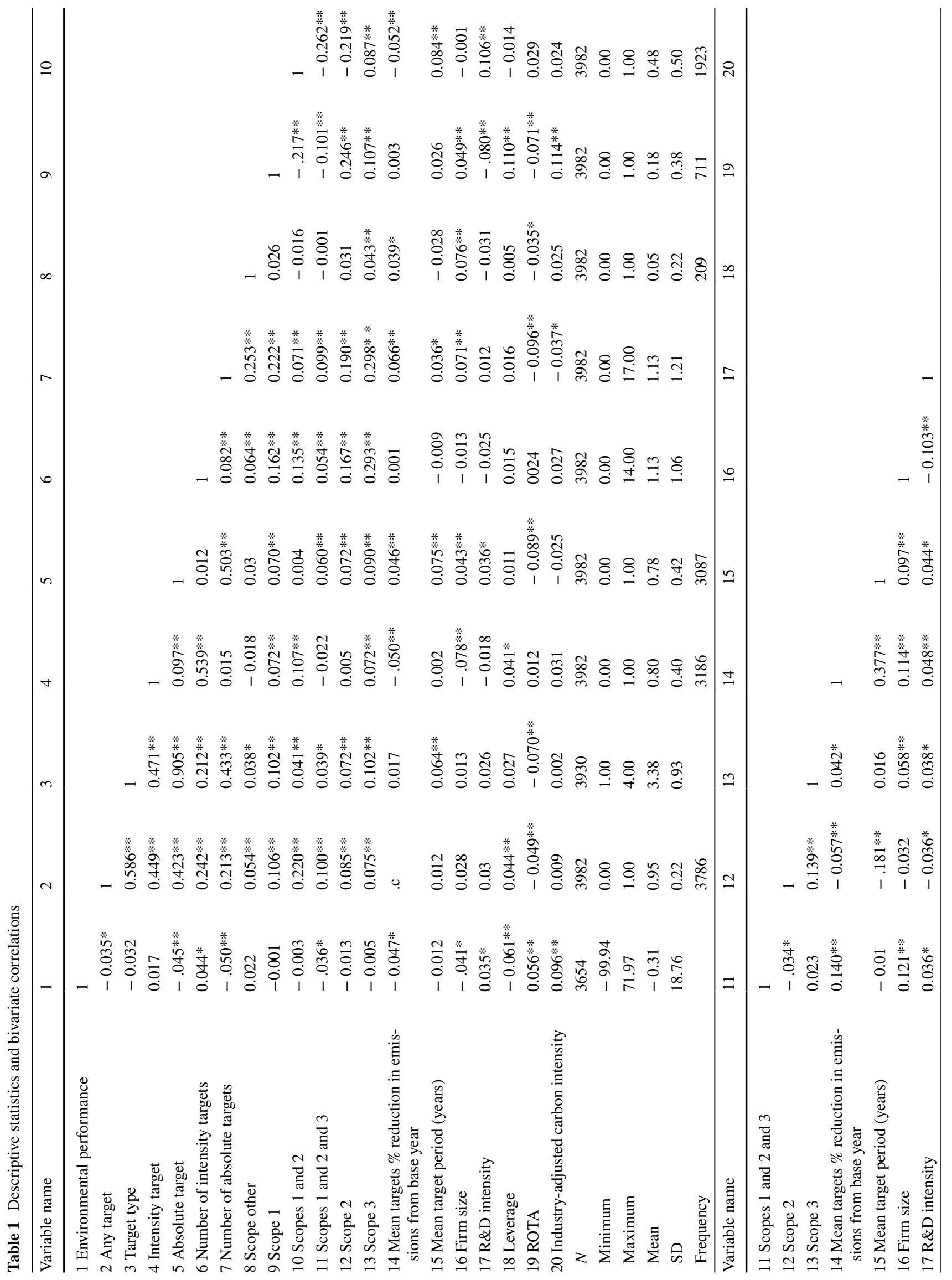




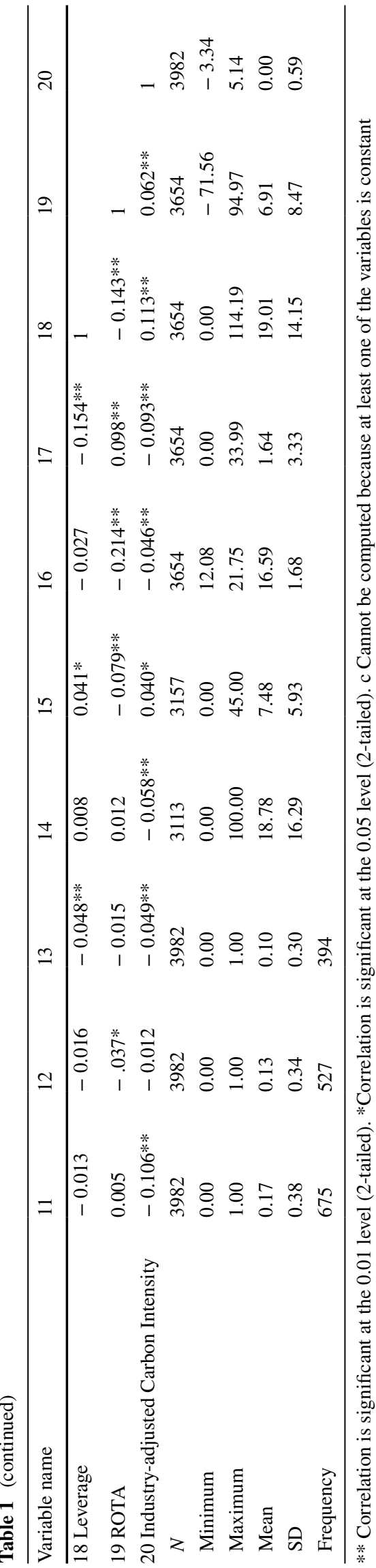

Table 2 Relationships between firm-level predictors and the presence of climate change targets

\begin{tabular}{|c|c|c|c|}
\hline \multirow[t]{2}{*}{ DV: Any target } & \multicolumn{3}{|l|}{1} \\
\hline & $B$ & Std. Error & Sig. \\
\hline Constant & -20.605 & 23134.7 & 0.999 \\
\hline Firm size & 0.537 & 0.123 & $0.000 * * *$ \\
\hline R\&D intensity & 0.097 & 0.067 & 0.145 \\
\hline Leverage & 0.026 & 0.012 & $0.031 * *$ \\
\hline ROTA & 0.021 & 0.02 & 0.303 \\
\hline $\begin{array}{l}\text { Industry-adjusted carbon } \\
\text { performance }(t-1)\end{array}$ & 0.210 & 0.278 & 0.450 \\
\hline Industry & \multicolumn{3}{|l|}{ Yes } \\
\hline Country & \multicolumn{3}{|l|}{ Yes } \\
\hline Year & \multicolumn{3}{|l|}{ Yes } \\
\hline Observations & \multicolumn{3}{|l|}{3654} \\
\hline$\%$ Correctly classified & \multicolumn{3}{|l|}{$94.14 \%$} \\
\hline-2 Log likelihood & \multicolumn{3}{|l|}{501.654} \\
\hline Cox \& Snell $R^{2}$ & \multicolumn{3}{|l|}{0.224} \\
\hline Nagelkerke $R^{2}$ & \multicolumn{3}{|l|}{0.692} \\
\hline
\end{tabular}

use the predicted likelihood values for every firm-year in our subsequent stage two analyses.

Table 3 shows the results of seven linear regression models in stage two that explore the influences of firms implementing specific climate change aspirations on subsequent changes in total GHG emissions. First, model 1 provides the key benchmark model in that it examines the influences on changes in firms' carbon emissions by only including firms' likelihood of having a climate change target in place. This base model includes controls for two-digit SIC industry classifications, countries-of-origin, years, and various other firm-level effects. It shows that only firms' level of leverage is significantly associated with changes in emissions. Specifically, firms with greater leverage appear to be associated with reductions in emissions. This initial observation remains constant throughout all our subsequent models and suggests that firms with greater borrowing appear to be more likely to reduce their emissions. By contrast, the probability of having any kind of climate change target in place is not significantly associated with changes in environmental performance. This means that there is no general relationship between firms having a climate change target and reductions in their emissions. We return to this important observation in our discussion.

Next, in model 2 we include the ordinal variable of target type finding that this is negatively and significantly associated with changes in environmental performance ( $b=-1.025 ; p=0.054)$. In other words, the greater the value of the target type, the more likely the firm is to reduce its emissions. Given that greater values (i.e., 3: absolute targets 


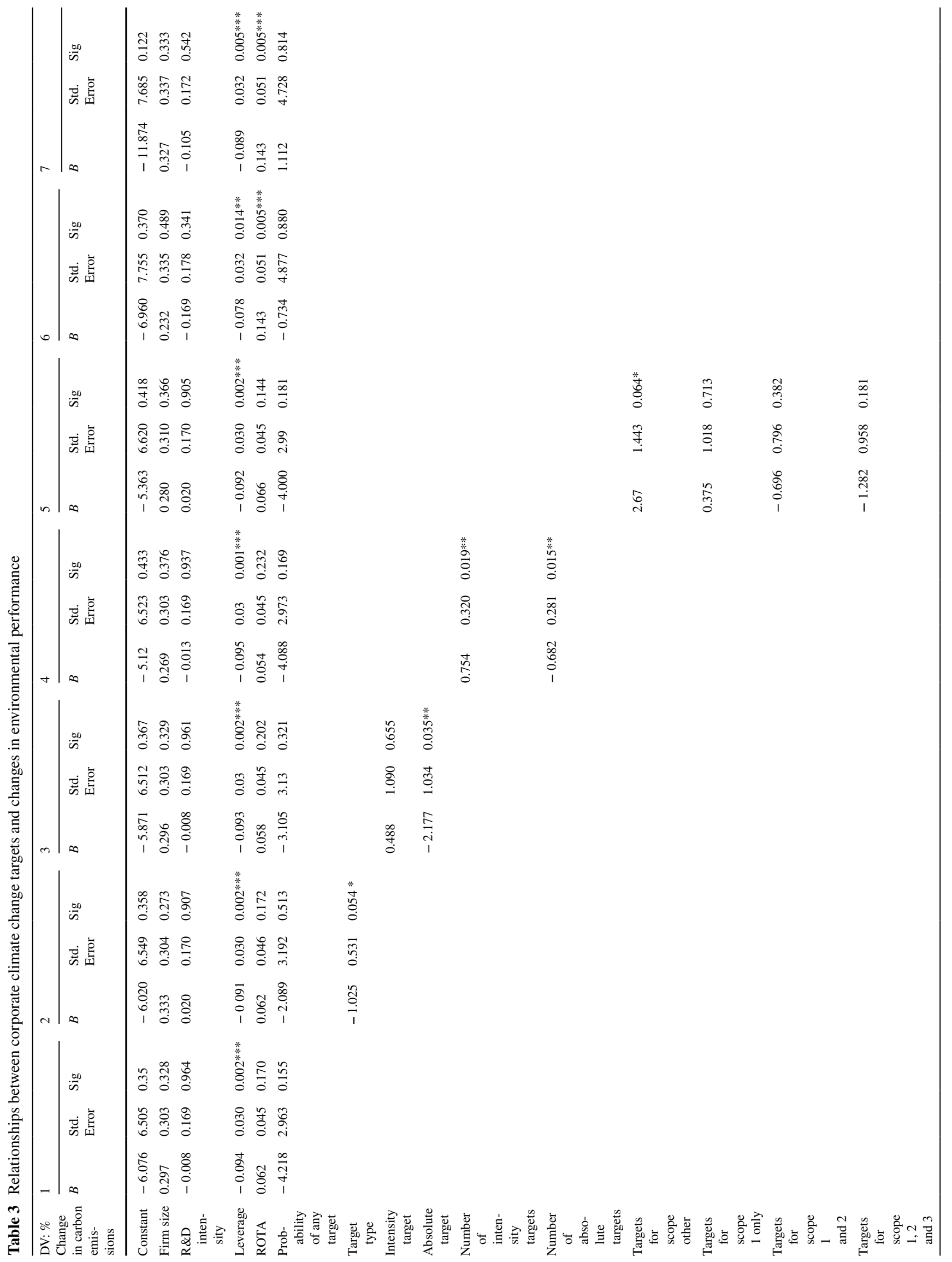




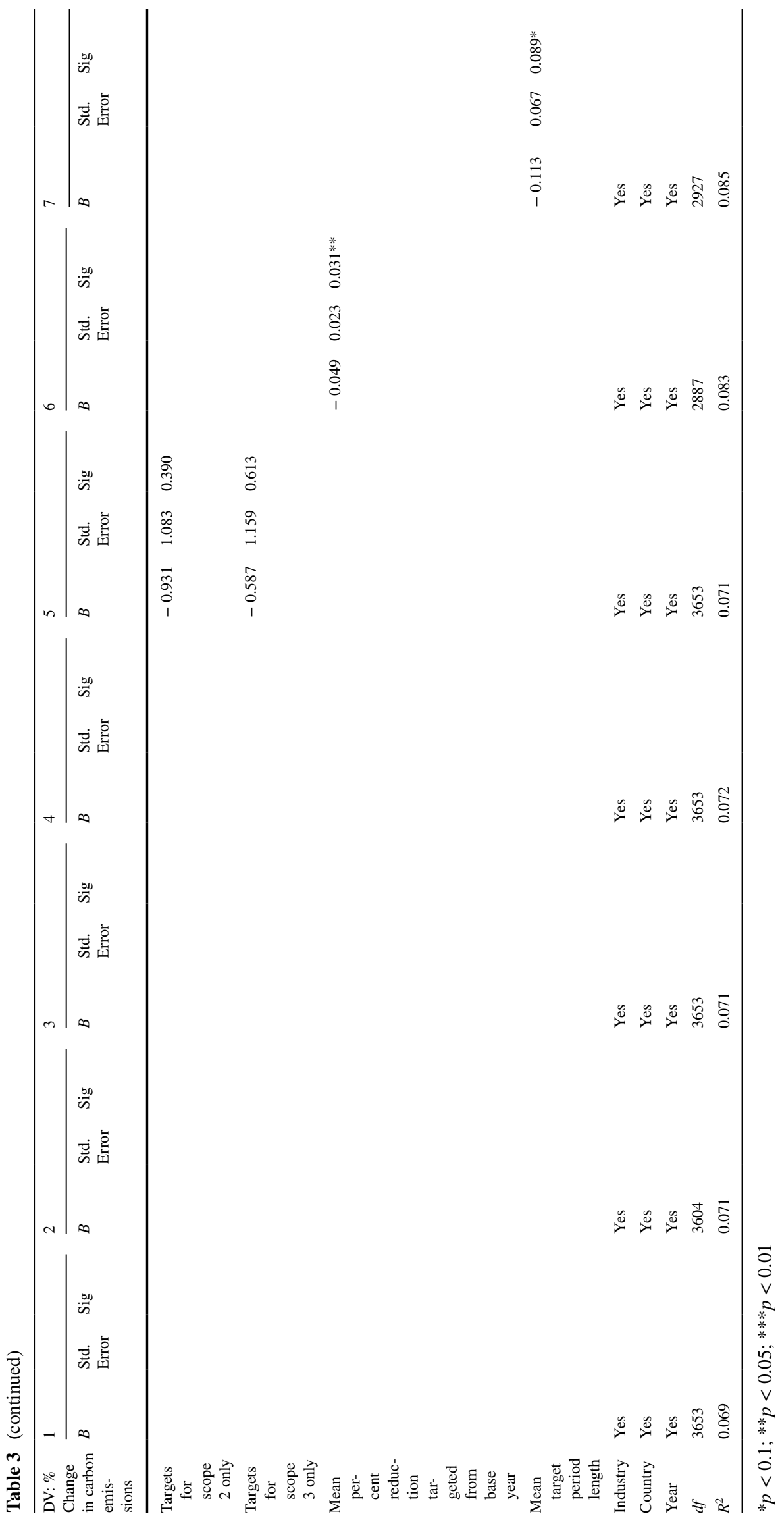


only; 4: intensity and absolute targets) are indicative of more substantive commitments toward addressing climate change, this is an important first result.

To explore this further, model 3 adds two binary variables for intensity and absolute targets to our base model. While we find no significant results for intensity targets, the presence of absolute targets is significantly and negatively associated with environmental performance $(b=-2.177$; $p=0.035$ ). Thus, corroborating findings from model 2 , the presence of absolute targets appears to be a strong predictor of companies reducing their GHG emissions. To explore this in more detail, model 4 replaces the previous two dummies with actual numbers of both intensity and absolute targets. We find that firms with more absolute targets are significantly and negatively associated with environmental performance $(b=-0.682 ; p=0.015)$, whereas firms with more intensity targets are significantly and positively associated with environmental performance $(b=0.754 ; p=0.019)$. While the effect size for absolute targets diminishes, statistical significance improves. By contrast, having more intensity targets appears to become a statistically significant indicator of firms engaging in symbolic climate change mitigation at best.

Next, model 5 compares the role of different climate change target scopes. Differentiating between different forms of direct and indirect emissions, only scope other emerges statistically significant and positive $(b=2.67 ; p=0.064)$. This suggests that by and large the emissions scope targeted by itself does not appear to affect subsequent environmental performance, except perhaps for targets on scope other than those referred to in the Greenhouse Gas Protocol (GHGP) (WBSCD/WRI 2011), but which do not appear to be associated with improvements.

Models 6 and 7 explore climate change target ambitiousness and time frames finding in both cases statistically significant and negative associations with environmental performance. Both firms with greater average emissions targets $(b=-0.049 ; p=0.031)$ and with longer target period lengths $(b=-0.113 ; p=0.089)$ appear to be linked to reductions in GHG emissions. Broadly, these findings provide interesting new insights into the role that different climate change target characteristics play as part of firms' efforts to address climate change.

Finally, to further account for firm- and industry-level contingencies affecting the potential for environmental improvement, we examine the extent to which the effectiveness of climate change targets is affected by firms' carbon dependency. As detailed in the methodology, we create two subsamples based on high and low carbon intensity or dependency. Tables 4 (low-carbon-dependency subsample) and 5 (high-carbon-dependency subsample) effectively mirror the models in Table 3 by running the same for our two subsamples.
In the case of the low-carbon-dependency subsample, our results closely resemble those of the complete sample in so far as that there is no statistical relationship between the likelihood of firms having any kind of climate change target and environmental performance (model 8). By contrast, results for target type (model $9 ; b=-1.75 ; p=0.042$ ), absolute targets (model 10; $b=-3.5 ; p=0.038$ ), and number of absolute targets (model $1 ; b=-0.902 ; p=0.043$ ) again appear to be statistically significant and negative, thus highlighting their importance in driving reductions in emissions. This time, however, while targets for scopes 1, 2 and 3 are associated with improvements in environmental performance (model 12; $b=-2.406 ; p=0.091$ ), climate change target ambitiousness and target time frame are not statistically significant.

Conversely, in the case of the high-carbon-dependency subsample, we only find statistically significant and positive associations between environmental performance and intensity targets (model $17 ; b=2.679 ; p=0.049$ ), the number of intensity targets (model $18 ; b=0.796 ; p=0.074$ ), and targets for scope other (model 19; $b=4.567 ; p=0.01$ ). Yet here climate change target ambitiousness (model 20; $b=-0.058 ; p=0.055$ ) and target time frame (model 21; $b=-0.173 ; b=0.062$ ) are both statistically significant and negative.

Generally speaking, our results lend support to our hypotheses that firms with absolute climate change targets, greater target ambitiousness, and longer target time frames are associated with improvements in environmental performance. This would corroborate our hypotheses $\mathrm{H} 1 \mathrm{~b}$, $\mathrm{H} 1 \mathrm{~d}$, and H1e. By contrast, we find no evidence for the role of a broader target scope in affecting emissions and thus reject H1c. Looking at the bigger picture, we differentiated between the presence of climate change targets generally (H1) and substantive climate change targets specifically (H1a). Our research consistently showed that the general presence of climate change targets is not associated with improvements in environmental performance, thus lending support for H1. Instead, by and large we find tentative first evidence to support an interpretation of substantive climate change targets as being instrumental in the achievement of emissions reductions. Except for H1c (target scope), the three other characteristics appear to be important indicators of the extent to which climate change targets have been specified in a substantive manner. These substantive climate change targets then appear to be linked to environmental performance improvements leading us to accept H1a.

Finally, our results also provide important insights into the contingencies affecting climate change target implementation. Specifically, we find evidence to suggest that different characteristics of substantive climate change targets appear to be effective tools for emissions reduction among firms with different levels of carbon dependency. While absolute 


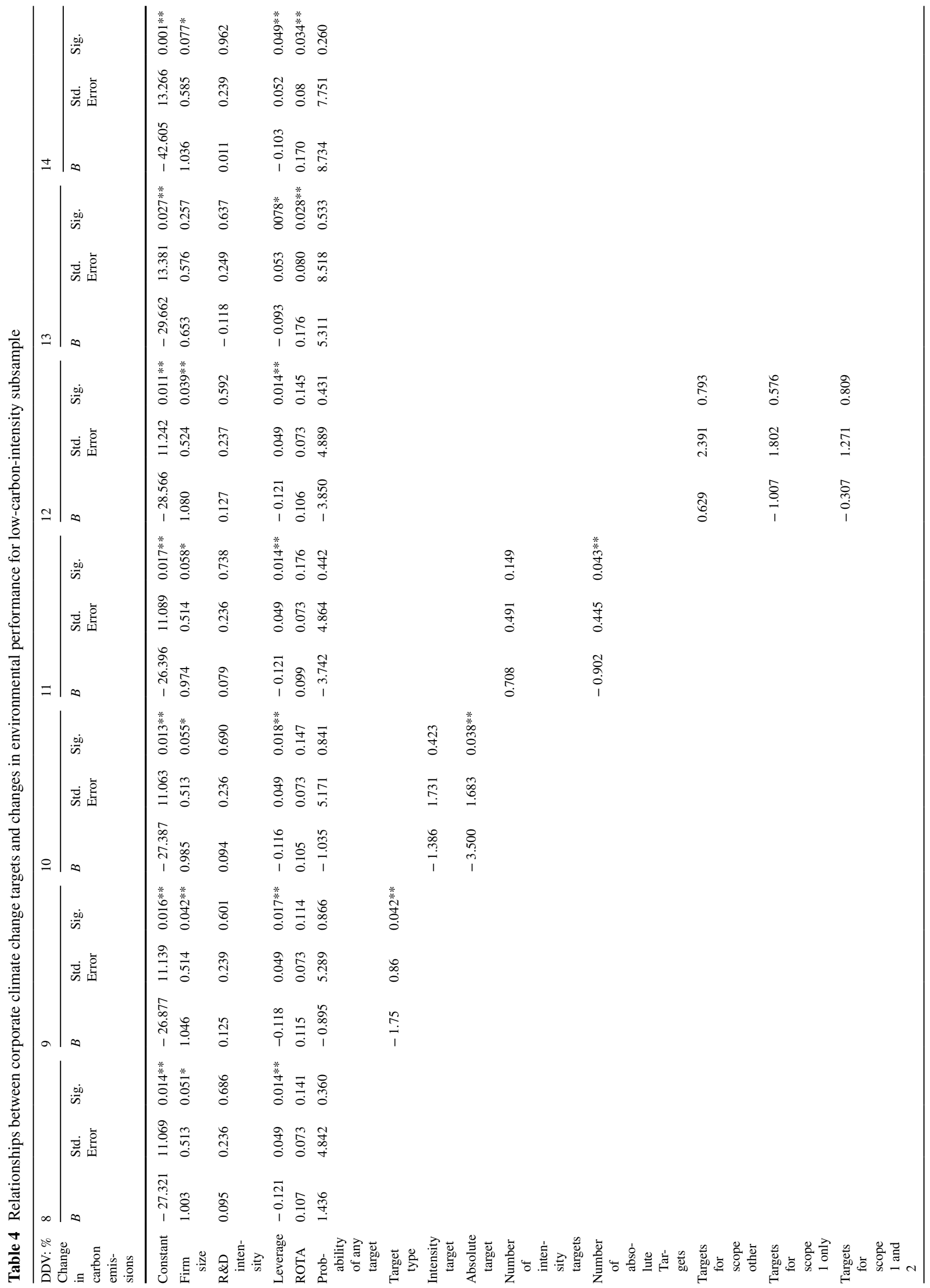




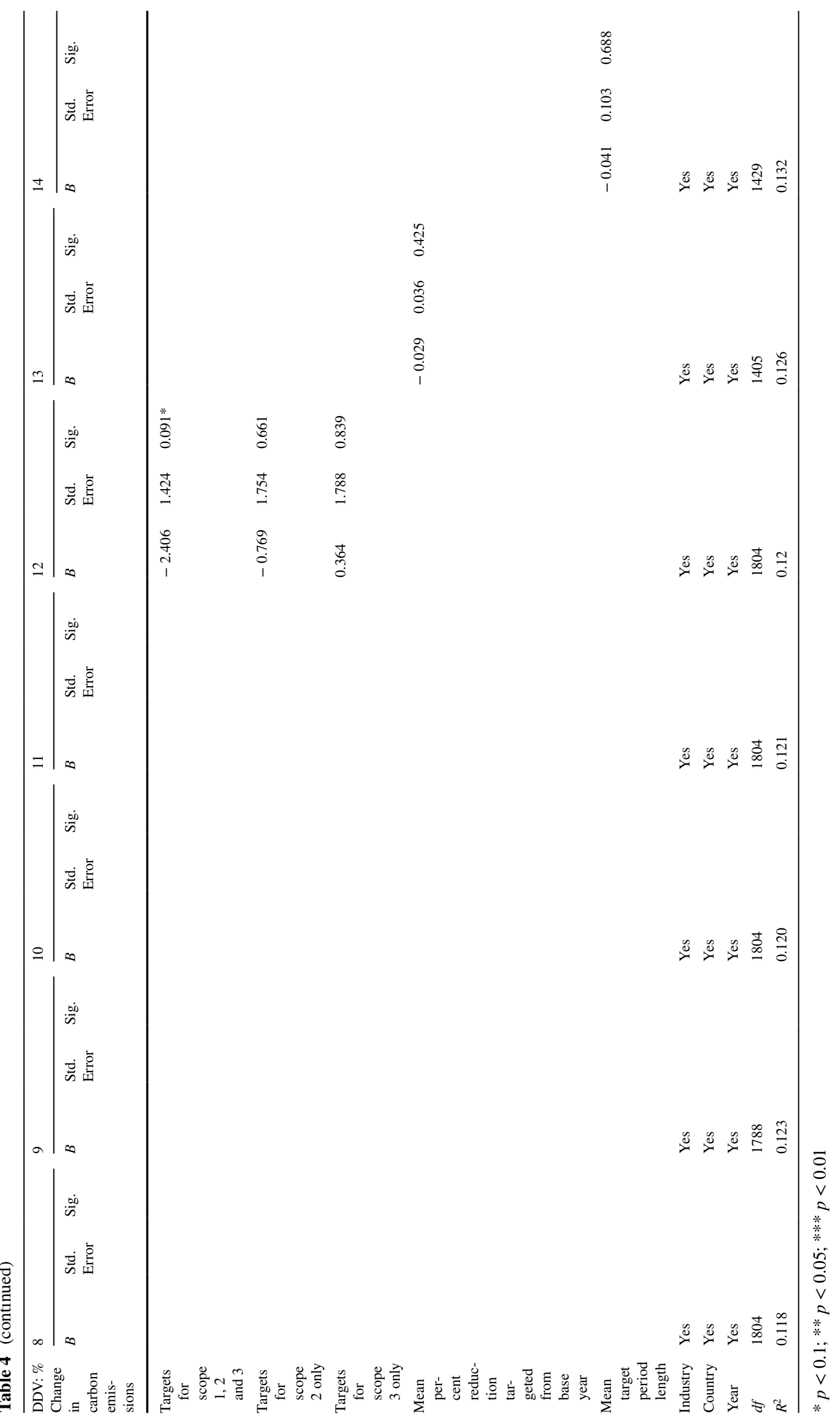




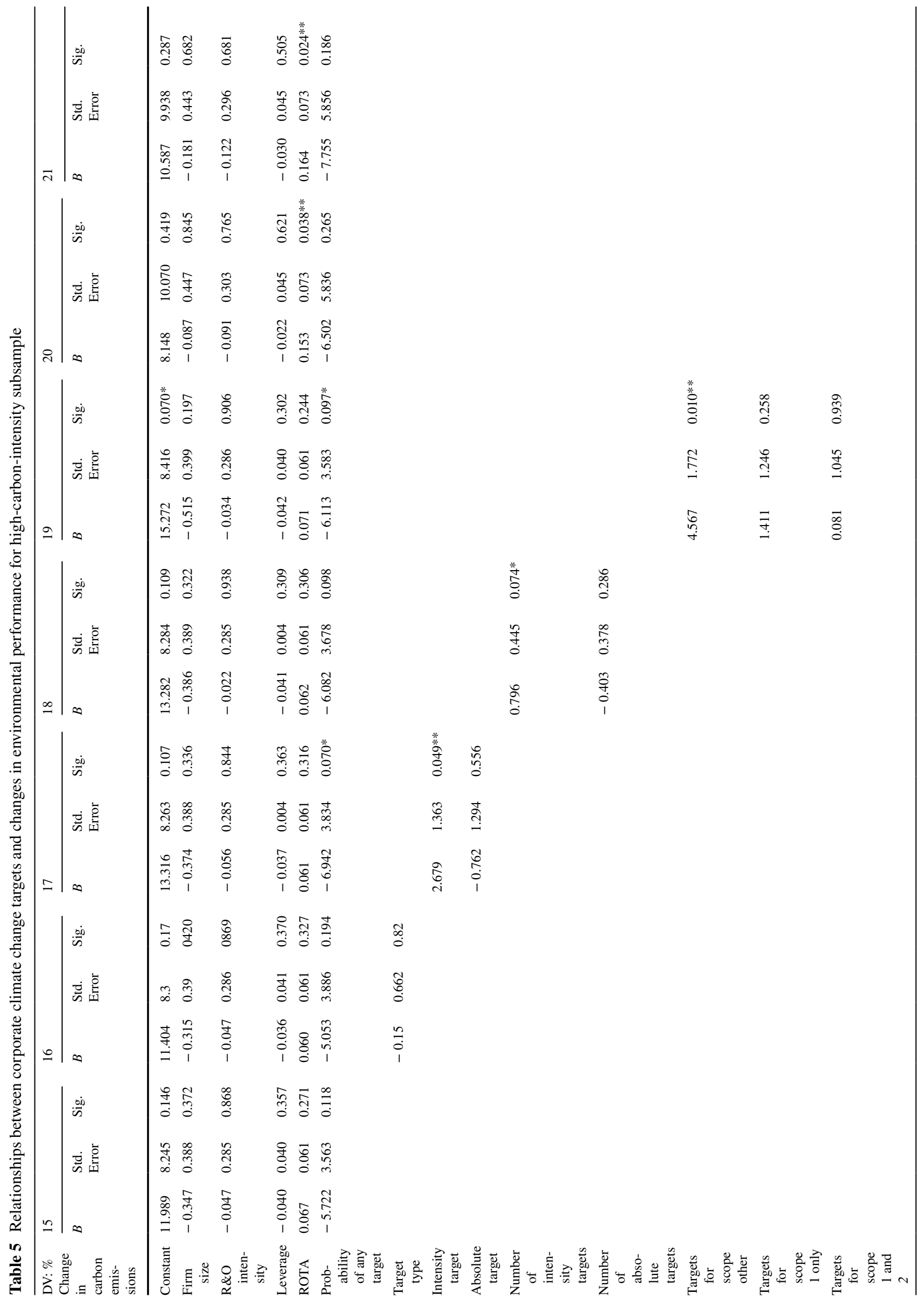




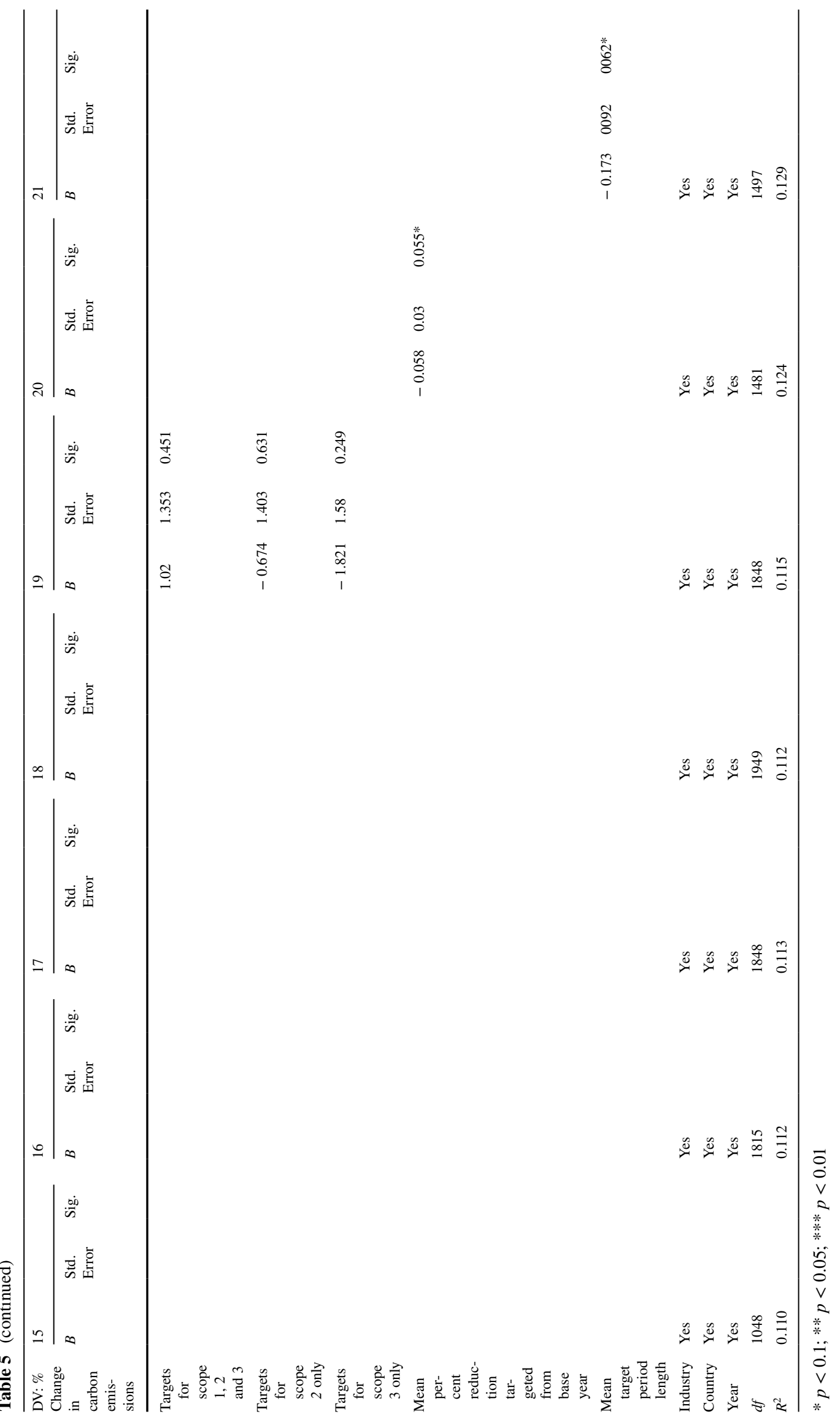


climate change target types and broad target scope are significantly associated with environmental improvements for firms with low carbon dependency, more ambitious and longer climate change targets seem to be effective in the context of high carbon dependency. This mixed picture therefore somewhat contradicts our hypothesis $\mathrm{H} 2$ which had argued that substantive climate change targets are only effective in the context of low carbon dependency. Instead, we find that while carbon dependency does indeed play a significant role, it appears to affect climate change target characteristics differentially. We therefore reject $\mathrm{H} 2$ and discuss the important conceptual, empirical, and practical questions and issues in our next section.

\section{Discussion}

In this paper, we investigate the relationships between the presence and nature of firms' climate change targets and changes in their corporate carbon footprints. Drawing on environmental management literature, we develop a conceptualization that views climate change targets as reflecting firms' range of strategic or symbolic intentions about environmental performance improvement. Distinguishing between symbolic and substantive intentions underpinning firms' ambitions for addressing climate change, we find support for our baseline hypothesis (H1) that generally there is no relationship between the presence of climate change targets and improvements in environmental performance. By contrast, only more substantive climate change targets are associated with reductions in firms' GHG emissions (H1a). These substantive intentions are identifiable by firms' climate change target characteristics.

Specifically, we find support for three of our four derived hypotheses on the role of corporate climate change target types, ambitiousness, and time frame. By contrast, we find no evidence in support of the role of a broader climate change target scope being indicative of substantive intentions to improve environmental performance. We see clear evidence that only absolute, rather than intensity targets appear to be associated with measurable reductions in carbon footprints, highlighting the need for unambiguous hard goals in the quest for significantly lower emissions. Intensity targets, by contrast, which seek performance improvements linked to specific measures of financial (e.g., per unit of sales) or operational (e.g., per kWh, employee, product type, etc.) output do not appear to reflect substantive enough intentions to address climate change. While undoubtedly beneficial from a micro-economic perspective, having intensity targets in place seems to create marginal effects from a corporate carbon footprint reduction perspective.

By contrast, we do not find resonance with our assertion that substantive intentions to reduce GHG emissions are more likely to be underpinned by a broader scope of emissions targeted. Except for the low-carbon-dependency subsample, there is no consistent evidence to support the claim that the scope of emissions targeted matters for the achievement of emissions reductions, except perhaps, when firms target scope outside the established GHG emissions protocol (WBSCD, WRI 2011). Here the results show increases in emissions, thus questioning this seemingly symbolic choice.

We also find some, though only weak, early evidence that target ambitiousness appears to reflect substantive intentions to reduce emissions. Consistent with theory, this level of stringency acts as a measure of the degree to which firms want to address historical or social performance gaps (Bromiley and Harris 2014; Washburn and Bromiley 2012), or develop strategic first-mover advantages (Pinkse and Busch 2013). Mirroring extant findings, we show that targets with a larger percentage of emissions to be reduced are indeed associated with environmental improvements (Ioannou et al. 2016; Maas 2016).

Equally, we can report a relationship between target time frames and environmental performance. Despite potentially opposing arguments, we find evidence for long-term target time frames being linked to emissions reductions. Having also tested (but not reported) the possibility of a curvilinear relationship, our results suggest that generally speaking climate change targets need to account for the significant changes required to adapt business models and practices. This is likely to play out over significant periods of time. Coupled with the radical nature of reducing emissions in absolute terms (while allowing for the potential to grow), this explains why climate change targets need to be realistic in terms of allowing for organizational change to occur. The fact that such long-term targets already appear to be linked to improvements suggests that managers do not use them to pass responsibility to future generations of managers but are able to start the organizational transformation. Ultimately, however, to demonstrate the effectiveness of target periods (whose mean is 7.5 years in our sample) significantly longer sampling periods will be necessary. One alternative hypothesis for future research might be that to be effective, firms need both targets with long and short time frames. This perspective would allow firms to aim for a long-term destination consistent with climate science, but which is made more manageable using short-term, interim targets, a practice Slawinski and Bansal (2015) called temporal ambidexterity. For this paper, however, longer target time frames appear to be indicative of substantive underlying intentions on improving firm-level environmental outcomes.

Finally, our analysis dissecting our sample into low- and high-carbon-dependency groups revealed a mixed picture. Although we generally find that results between the two subsamples differ, there is no striking evidence to suggest that substantive climate change targets are only effective in 
low-carbon-dependency contexts. In fact, different aspects of substantive climate change targets appear to be effective in different carbon dependency contexts. While target type (i.e., absolute targets) and broader target scope (i.e., 1, 2\&3) appear to matter in the low-carbon-dependency sample, more quantitative characteristics such as target ambitiousness and target time frame are important in the high-carbondependency sample. This suggests that carbon dependency may not be the key variable shaping the effectiveness of climate change targets as suggested in our second hypothesis. Instead, it provides context-specific contingencies for the different messages that climate change target characteristics signal to employees and other affected stakeholders.

Our paper confirms and contributes to the discussions about understanding voluntary environmental practices through the lens of substantive and symbolic intentions (Bansal and Clelland 2004; Berrone and Gomez-Mejia 2009; Boiral 2007; Delmas and Toffel 2008; Delmas and MontesSancho 2010). We extend this core conceptualization in the sustainability literature by demonstrating its relevance for and application in the context of corporate climate change ambitions. We highlight that though some practices may at first appear to follow similar objectives, in fact the underlying intentions may differ significantly. Corporate climate change targets vary in their implementation, and this heterogeneity can be explained as an expression of firms' espoused beliefs about the need for, and purposes of, setting such targets. While operationalization remains fraught with limitations, our research gives first empirical insights into the variation of approaches and their respective effectiveness when it comes to reducing corporate carbon footprints.

Our research also shines new light on the use of organizational aspirations in the context of non-financial performance (Di Norcia 1996; Ioannou et al. 2016; Maas and Rosendaal 2016; Russo and Harrison 2005). While extant research on aspirations suggests that they may be valuable tools for fostering financial performance improvements, our research adds to the discussions about their ambiguity in terms of intentions and effectiveness (Kolk and Perego 2014). A key difference between financial and non-financial performance targets is the potentially oblique way in which these targets operate. Apart from pure, ethical motivations to address climate change, wider more strategic intentions to reduce firms' GHG emissions may (eventually) lead to financial performance and other benefits, however, in more indirect ways. This relationship is heavily context specific and firm specific but would explain why some firms voluntarily set ambitious targets based on substantive intentions to reduce their emissions. We therefore extend previous research that studied the role of quantitative, hard targets as part of executive compensation in improving corporate sustainability outcomes (Maas 2016) by highlighting the significance of implementing measureable targets for the entire firm rather than upper echelons only. Given the recent burgeoning of target-driven sustainability initiatives, understanding whether and how such ambitions are likely to succeed will help shape practice in this area.

Moreover, we argued that while commensurability in terms of outcomes may be achieved as part of substantive approaches which can be driven by both strategic and ethical considerations (Hahn et al. 2016), alternative, more symbolic approaches designed to enhance organizational legitimacy in the eyes of stakeholders are likely to attract accusations of greenwash when non-financial performance outcomes are investigated (Aragón-Correa et al. 2016; Berrone et al. 2017; Delmas and Burbano 2011; Pinkse and Busch 2013). We show that firms set a variety of climate change targets, but for various reasons it is challenging to decouple total GHG emissions from financial and operational performance (i.e., reduce total emissions while potentially continuing to grow). We argue only absolute targets represent a true and scientifically justifiable approach toward limiting climate change. The fact that other business priorities provide constant challenges to these targets (e.g., business growth and expansion, $M \& A$ activity, etc.) is one of the uncomfortable truths behind setting substantive climate change targets. Our results that substantive climate change targets are associated with short-run improvements (i.e., reductions in firms' total emissions regardless of firm growth) can be interpreted as a tentatively positive sign. It suggests that improvements are indeed possible, despite numerous economic and operational obstacles. Undoubtedly, firms will face problems along the way of achieving their targets, but as long as they are broadly in line with the desired long-run aspirations, this is something to be commended and strengthened.

By contrast, firms setting relatively more symbolic targets are clearly engaging in a form of greenwash designed to give the impression of caring about climate change while largely continuing with business as usual (Lyon and Maxwell 2011; Lyon and Montgomery 2015). Stakeholders must therefore be weary of any such signals and commitments which may give off the appearance of concern while being as effective as not having any targets at all. Efficiency improvements are important and should be acknowledged as improvements, nonetheless, but in the face of business growth, they continue to add to the cumulative total of global GHG emissions and thus do not align with scientific assessments and recent political agreements that demand absolute reductions at global (and thus firm) levels.

In sum, our research opens the debate for wider discussions about the interactions of strategic, ethical, and symbolic intentions in the context of aspirations: For example, to what extent are symbolic intentions underpinning target setting truly recognized as creating legitimacy by stakeholders? How do employees respond to such comparatively superficial targets? Are there any financial performance 
implications? Understanding the complex relationships between substantive and symbolic intentions, ethical and strategic considerations as well as both financial and nonfinancial performance outcomes will help in disentangling the general nuances and contingencies of organizational aspirations. Knowledge in this area may also inform research on other types of corporate responsibility targets such as minority hiring and female board participation.

\section{Limitations}

Our research is bounded by methodological limitations inherent in working with voluntarily disclosed secondary data, particularly given the still developing nature of this field. We acknowledge the critiques and questions surrounding our dataset, but hope to have provided assurance that our approach is robust. Recent legislative efforts to make carbon disclosure mandatory for all large firms and investor-led efforts toward standardization ${ }^{3}$ will hopefully lead to more comprehensive and consistent datasets in future. This would aid replicability of our research, overcome the selection bias of firms reporting to the CDP, and address concerns that the self-reporting of targets and achievements (i.e., GHG emissions) presents opportunities for unethical behavior such as misrepresenting improvements.

While we investigate several years of data, many of our effects are likely to require even longer periods of observation to manifest themselves. Our approach was guided by concerns for data validity and availability. Again, with growing and more consistently managed data collection, future analyses will be able to help shed further light on the relationship between corporate carbon aspirations and environmental performance, especially target scopes and time frames. Given the significant challenges involved in decarbonizing the global economy and individual companies, assessing the endurance of our findings will require many more years of emissions performance under observation. Then, research could also substantiate the extent to which firms actually achieve their self-stated goals.

Finally, while we sought to highlight general trends and relationships between corporate climate change targets and carbon footprints, there is also a need to drill deeper into target-setting behaviors at the firm level. Given that many of our variables are ultimately aggregated data points, in situ observations of the target setting and organizational response processes are likely to yield a much richer understanding of the intentions and considerations driving individuals within firms when it comes to implementing and responding to such targets. For example, the Science-Based Targets

${ }^{3}$ See, for example, the Taskforce on Climate Related Financial Disclosure https://www.fsb-tcfd.org/ initiative provides an interesting research opportunity to follow organizations on their journey toward setting substantive climate change targets. Using firm- and industry-level cases studies could help in understanding how to grow this movement through increased participation and thus significantly increase the potential for business to play its part in addressing climate change.

\section{Conclusion}

There is a recognized, and growing, gap between the rates of reduction in global carbon emissions necessary to mitigate the most harmful effects of climate change and the reductions being achieved in most economies (UNEP 2015; UNFCCC 2015). Meeting internationally agreed plans for sustainable development will require a step change in progress on emissions reduction, and businesses, as major emitters, need to find ways to accelerate progress on reducing their carbon footprints. In this paper, we explored whether corporate aspirations for reductions in carbon emissions translate into actual improvements in non-financial performance in the context of a large multi-country sample of companies. Building on extant conceptualizations that distinguish between substantive and symbolic intentions underpinning firms' voluntary environmental practices, we find evidence in support of our hypotheses that only absolute targets, longer target time frames, and greater levels of target ambitiousness are associated with improvements in environmental performance. While our research does not differentiate between strategic and ethical justifications of such targets, it supports the notion that ultimately only substantive (as opposed to symbolic) intentions for corporate aspirations are likely to overcome the most pressing ethical challenges facing contemporary business and society (Howard-Grenville et al. 2014; Vatican 2016).

\section{Compliance with Ethical Standards}

Conflict of interest The authors of this manuscript Dr. Dahlmann, Dr. Branicki, and Professor Brammer declare that they have no conflicts of interest.

Ethical Approval This article does not contain any studies with human participants or animals performed by any of the authors.

Open Access This article is distributed under the terms of the Creative Commons Attribution 4.0 International License (http://creativecommons.org/licenses/by/4.0/), which permits unrestricted use, distribution, and reproduction in any medium, provided you give appropriate credit to the original author(s) and the source, provide a link to the Creative Commons license, and indicate if changes were made. 


\section{References}

Alt, E., Díez-de-Castro, E. P., \& Lloréns-Montes, F. J. (2015). Linking employee stakeholders to environmental performance: The role of proactive environmental strategies and shared vision. Journal of Business Ethics, 128, 167-181.

Andrew, J., \& Cortese, C. (2011). Accounting for climate change and the self-regulation of carbon disclosures. Accounting Forum, 35, $130-138$

Aragón-Correa, J. A., Marcus, A., \& Hurtado-Torres, N. (2016). The natural environmental strategies of international firms: Old controversies and new evidence on performance and disclosure. Academy of Management Perspectives, 30, 24-39.

Bansal, P. (2003). From issues to actions: The importance of individual concerns and organizational values in responding to natural environmental issues. Organization Science, 14, 510-527.

Bansal, P. (2005). Evolving sustainably-A longitudinal study of corporate sustainable development. Strategic Management Journal, 26, 197-218.

Bansal, P., \& Clelland, I. (2004). Talking trash: Legitimacy, impression management, and unsystematic risk in the context of the natural environment. Academy of Management Journal, 47, 93-103.

Belsley, D. A., Kuh, E., \& Welsch, R. E. (1980). Regression diagnostics. New York, NY: Wiley.

Berrone, P., Fosfuri, A., \& Gelabert, L. (2017). Does greenwashing pay off? Understanding the relationship between environmental actions and environmental legitimacy. Journal of Business Ethics, 144, 363-379.

Berrone, P., \& Gomez-Mejia, L. R. (2009). Environmental performance and executive compensation: An integrated agency-institutional perspective. Academy of Management Journal, 52, 103-126.

Besio, C., \& Pronzini, A. (2014). Morality, ethics, and values outside and inside organizations: An example of the discourse on climate change. Journal of Business Ethics, 119, 287-300.

Boiral, O. (2007). Corporate greening through ISO 14001: A rational myth? Organization Science, 18, 127-146.

Bowen, F. (2014). After Greenwashing-Symbolic corporate environmentalism and society. Cambridge: Cambridge University Press.

Bowen, F. (2017). Marking their own homework: The pragmatic and moral legitimacy of industry self-regulation. Journal of Business Ethics. https://doi.org/10.1007/s10551-017-3635-y.

Branzei, O., Ursacki-Bryant, T. J., Vertinsky, I., \& Zhang, W. (2004). The formation of green strategies in Chinese firms: Matching corporate environmental responses and individual principles. Strategic Management Journal, 25, 1075-1095.

Bromiley, P., \& Harris, J. D. (2014). A comparison of alternative measures of organizational aspirations. Strategic Management Journal, $35,338-357$

Bundy, J., Shropshire, C., \& Buchholtz, A. K. (2013). Strategic cognition and issue salience: Toward an explanation of firm responsiveness to stakeholder concerns. Academy of Management Review, 38, 352-376.

CDP (2017). Supply chain report 2017. https://www.cdp.net/en/ research/global-reports/global-supply-chain-report-2017. Accessed March 172017.

Chen, C. M. (2017). Supply chain strategies and carbon intensity: The roles of process leanness, diversification strategy, and outsourcing. Journal of Business Ethics, 143(3), 603-620.

Collins, J. C., \& Porras, J. (1994). Built to last: Successful habits of visionary companies. New York: Harper Business.

Cordano, M., \& Frieze, I. H. (2000). Pollution reduction preferences of U.S. environmental managers: Applying Ajzen's theory of planned behavior. Academy of Management Journal, 43, 627-641.
Cordeiro, J. J., \& Sarkis, J. (2008). Does explicit contracting effectively link CEO compensation to environmental performance? Business Strategy and the Environment, 17, 304-317.

Crilly, D., Zollo, M., \& Hansen, M. T. (2012). Faking it or muddling through? Understanding decoupling in response to stakeholder pressures. Academy of Management Journal, 55, 1429-1448.

Darnall, N., Henriques, I., \& Sadorsky, P. (2010). Adopting proactive environmental strategy: The influence of stakeholders and firm size. Journal of Management Studies, 47, 1072-1094.

Delmas, M. A., \& Burbano, V. C. (2011). The drivers of greenwashing. California Management Review, 54, 64-87.

Delmas, M. A., \& Montes-Sancho, M. J. (2010). Voluntary agreements to improve environmental quality: Symbolic and substantive cooperation. Strategic Management Journal, 31, 575-601.

Delmas, M. A., \& Toffel, M. W. (2008). Organizational responses to environmental demands: Opening the black box. Strategic Management Journal, 29, 1027-1055.

Di Norcia, V. (1996). Environmental and social performance. Journal of Business Ethics, 15, 773-784.

Eccles, R. G., Krzus, M. P., Rogers, J., \& Serafeim, G. (2012). The need for sector specific materiality and sustainability reporting standards. Journal of Applied Corporate Finance, 24, 65-71.

Flammer, C. (2013). Corporate social responsibility and shareholder reaction: The environmental awareness of investors. Academy of Management Journal, 56, 758-781.

Foss, N. J., \& Lindenberg, S. (2013). Microfoundations for strategy: A goal-framing perspective on the drivers of value creation. Academy of Management Perspectives, 27, 85-102.

Hahn, T., Pinkse, J., Preuss, L., \& Figge, F. (2016). Ambidexterity for corporate social performance. Organization Studies, 37, 213-235.

Hahn, T., Preuss, L., Pinkse, J., \& Figge, F. (2014). Cognitive frames in corporate sustainability: Managerial sensemaking with paradoxical and business case frames. Academy of Management Review, 39, 463-487.

Hahn, R., Reimsbach, D., \& Schiemann, F. (2015). Organizations, climate change, and transparency reviewing the literature on carbon disclosure. Organization \& Environment, 28, 80-102.

Halme, M. (2002). Corporate environmental paradigms in shift: Learning during the course of action at UPM-Kymmene. Journal of Management Studies, 39, 1087-1109.

Haney, A. B. (2015). Threat interpretation and innovation in the context of climate change: An ethical perspective. Journal of Business Ethics, 1-16, forthcoming.

Heckman, J. T. (1979). Sample selection bias as a specification error. Econometrica, 47, 153-161.

Howard-Grenville, J., Buckle, S. J., Hoskins, B. J., \& George, G. (2014). Climate change and management. Academy of Management Journal, 57, 615-623.

Hussain, N., Rigoni, U., \& Orij, R. P. (2016). Corporate governance and sustainability performance: Analysis of triple bottom line performance. Journal of Business Ethics. https://doi. org/10.1007/s10551-016-3099-5.

Ioannou, I., Li, S. X., \& Serafeim, G. (2016). The effect of target difficulty on target completion: The case of reducing carbon emissions. The Accounting Review, 91, 1467-1492.

Kolk, A., \& Perego, P. (2014). Sustainable bonuses: Sign of corporate responsibility or window dressing? Journal of Business Ethics, 119, 1-15.

Locke, E. A., \& Latham, G. P. (2009). Has goal setting gone wild, or have its attackers abandoned good scholarship? Academy of Management Perspectives, 23, 17-23.

Luo, L. L. (2017). The influence of institutional contexts on the relationship between voluntary carbon disclosure and carbon emission performance. Accounting and Finance. https://doi. org/10.1111/acfi.12267. 
Lyon, T. P., \& Maxwell, J. W. (2011). Greenwash: Corporate environmental disclosure under threat of audit. Journal of Economics \& Management Strategy, 20, 3-41.

Lyon, T. P., \& Montgomery, A. W. (2015). The means and end of greenwash. Organization \& Environment, 28, 223-249.

Maas, K. (2016). Do corporate social performance targets in executive compensation contribute to corporate social performance? Journal of Business Ethics. https://doi.org/10.1007/s10551-015-2975-8.

Maas, K., \& Rosendaal, S. (2016). Sustainability targets in executive remuneration: Targets, time frame, country and sector specification. Business Strategy and the Environment, 25, 390-401.

Mishina, Y., Dykes, B. J., Block, E. S., \& Pollock, T. G. (2010). Why "good" firms do bad things: The effects of high aspirations, high expectations, and prominence on the incidence of corporate illegality. Academy of Management Journal, 53, 701-722.

O'Brien, R. M. (2007). A caution regarding rules of thumb for variance inflation factors. Quality \& Quantity, 41, 673-690.

Pache, A.-C., \& Santos, F. (2013). Inside the hybrid organization: Selective coupling as a response to competing institutional logics. Academy of Management Journal, 56, 972-1001.

Pinkse, J., \& Busch, T. (2013). The emergence of corporate carbon norms: Strategic directions and managerial implications. Thunderbird International Business Review, 55, 633-645.

Pinkse, J., \& Kolk, A. (2009). International business and global climate change. Abingdon: Routledge. ISBN 0-203-88710-7.

Porter, M. E., \& Van der Linde, C. (1995). Toward a new conception of the environment-competitiveness relationship. The Journal of Economic Perspectives, 9, 97-118.

Post, C., Rahman, N., \& McQuillen, C. (2015). From board composition to corporate environmental performance through sustainability-themed alliances. Journal of Business Ethics, 130, 423-435.

Russo, M. V., \& Harrison, N. S. (2005). Organizational design and environmental performance: Clues from the electronics industry. Academy of Management Journal, 48, 582-593.

Sharma, S. (2000). Managerial interpretations and organizational context as predictors of corporate choice of environmental strategy. Academy of Management Journal, 43, 681-697.

Sitkin, S. B., See, K. E., Miller, C. C., Lawless, M. W., \& Carton, A. M. (2011). The paradox of stretch goals: Organizations in pursuit of the seemingly impossible. Academy of Management Review, $36,544-566$.
Slawinski, N., \& Bansal, P. (2012). A matter of time: The temporal perspectives of organizational responses to climate change. Organization Studies, 33, 1537-1563.

Slawinski, N., \& Bansal, P. (2015). Short on time: Intertemporal tensions in business sustainability. Organization Science, 26, 531-549.

Slawinski, N., Busch, T., Pinkse, J., \& Banerjee, S. B. (2017). The role of short-termism and uncertainty avoidance in organizational inaction on climate change: A multi-level framework. Business and Society, 56, 253-282.

Stern, N. (2006). Stern review on the economics of climate change. HM Treasury/Cabinet Office. http://webarchive.nationalarchives. gov.uk/+/http:/www.hm-treasury.gov.uk/sternreview_index.htm. Accessed March 132017.

UNEP (2015). The emissions gap report 2015. United Nations Environment Programme, November 2015. http://uneplive.unep.org/ theme/index/13\#indcs. Accessed August 152016.

UNFCCC (2015). Adoption of the Paris agreement. UNFCC, Paris: 12 December 2015. UN FCCC/CP/2015/L.9/Rev.1. https://unfccc. int/resource/docs/2015/cop21/eng/109r01.pdf. Accessed August 122016

Unruh, G. C. (2002). Escaping carbon lock-in. Energy Policy, 30, $317-325$.

Vatican (2016). Encyclical letter Laudato Si' of the Holy Father Francis on care for our common home. https://laudatosi.com/watch. Accessed March 132017.

Washburn, M., \& Bromiley, P. (2012). Comparing aspiration models: The role of selective attention. Journal of Management Studies, 49, 896-917.

WBSCD, WRI. (2011). The greenhouse gas protocol corporate standard. Geneva: The Greenhouse Gas Protocol.

Winter, S. G. (2000). The satisficing principle in capability learning. Strategic Management Journal, 21, 981-996.

Wright, C., \& Nyberg, D. (2016). An inconvenient truth: How organizations translate climate change into business as usual. Academy of Management Journal, forthcoming.

Zhang, Z., \& Jia, M. (2013). How can companies decrease the disruptive effects of stretch goals? The moderating role of interpersonal- and informational- justice climates. Human Relations, 66, 993-1020. 